DOI: 10.17707/AgricultForest.62.1.14

Antoine SHOMAR, Khaled EL SHAMAA ${ }^{1}$

\title{
IDENTIFYING SOME HERBICIDE RESISTANT GRASSES, MONITORING THEIR NATURE AND DISTRIBUTION IN SOUTHWESTERN PART OF ALEPPO CITY, SYRIA
}

\section{SUMMARY}

It is common to say that weeds in Syria have developed resistance to herbicides, but this needs to be confirmed by research studies which are rare in the area. This study is run to describe and diagnose those weeds, and to monitor their nature and allocate their distribution in the Quaik river area in the southwestern part of Aleppo city in Syria. Seeds of suspected resistant grasses have been collected during the 2010 summer from Al-Eis, Al-Hadher and Banes, which were theoretically identified as resistant biotype to (ACCase) herbicides. In addition to seeds of grasses collected from ICARDA Tel Hadya station which were expected as sensitive biotype, taking into account that the seeds were preserved properly for the 2011/2012 season. In this experiment four herbicides have been used, two ACCase inhibitors, Ralon super (fenoxaprop-p-ethyl) and Topik (clodinafobpropargyl), the other two ALS inhibitors, Atlantis (mesosulfuron + iodosulfuron) and Pallas (pyroxsulam). The results showed that, the short spike canarygrass (Phalaris brachystachys L.) was the most risky in this area which have developed resistance to the (ACCase) in all locations including Tel Hadya station, the hood canarygrass (Phalaris paradoxa L.) came second in its resistance shown to the (ACCase) at all locations except Tel Hadya station. The wild oat (Avena fatua L.) came third, the results shown developed resistance to the (ACCase) in two locations Al-Hadher and Banes, sensitive in Tel Hadya station, while the results at Al-Eis were uncertain.

Keywords: Bioassay, discriminating dose, herbicides resistance, seed sampling, site of action.

\section{INTRODUCTION}

Herbicide resistance is the genetic capacity of weed population to survive herbicides treatment that, under normal use conditions, would effectively control that weed population. It is an example of evolution happening at an accelerated pace and an illustration of the "survival of the fittest" principle. Applying the same herbicide in the same field year after year will select resistant plants. The resistant weeds may eventually dominate the population. However, the first herbicide-resistant weed was discovered in 1968 (Ryan, 1970). In the next two decades, there have been numerous reports of weed biotypes exhibiting

\footnotetext{
${ }^{1}$ Antoine Shomar, Khaled El Shamaa, (corresponding author: a.shomar@cgiar.org), International Center for Agricultural Research in the Dry Areas (ICARDA), Aleppo, SYRIA.

Paper presented at the $6^{\text {th }}$ International Scientific Agricultural Symposium "AGROSYM 2015".

Notes: The authors declare that they have no conflicts of interest. Authorship Form signed online.
} 
resistance to photosystem II inhibiting herbicides (Bandeen et al, 1982). Ian Heap presented a graphs were made from data accessed from the survey website (WSSA, 2014) show the chronological increase in unique cases of herbicide resistant weeds (almost 440 cases). Grasses which is our interest in this study are involving the inhibition of acetyl-CoA carboxylase (ACCase). Lipids are involved in the biogenesis and function of various membranes, cellular signal transduction and other physiological functions (Browse and Somerville, 1991). Herbicide resistant, related (WSSA, 2004) doesn't mentioned any case of herbicide resistant in Syria, while the same reference referred to two cases in Turkey, and one case in Saudi Arabia, both registered as ACCase inhibitors, as well as 19 cases in (Israel), 2 registered as ACCase inhibitors. If the objective of a survey is to determine the occurrence of resistance in one or more weed species to a particular herbicide, fields treated with these herbicides in the growing season when the survey is conducted can be identified by randomly contacting growers in the study area (Beckie et al. 1999a, 1999b). Actually this is wellmatched with the farmers of Euphrates river area as they have complained from grasses herbicides, the main complaint was wild oat. The rationale reason was this grass became herbicide-resistant for ACCase inhibitors, because this herbicide group was commonly used since decades. However, new herbicides have been available in Syria recently to control weeds in cereals, by different mode of action, ALS inhibitors. Several demonstration trials applied in 2006 and 2007 in that region clearly indicated the efficiency of herbicide (ALS) in comparison with the conventional herbicides that prevailed for so long (ACCase). The phenomenon was repeated later in the southwestern region of Aleppo, where farmers complained from the herbicides, which were used to control grasses in broad leaf crops, those herbicides are ACCase inhibitors. The Canary grass was the most troublesome weed in this region and obviously was putative resistant to those herbicides. Several demonstration trials applied in 2007, 2008 and 2009 in Quaik river region clearly indicated the efficiency of herbicide (ALS) in comparison to (ACCase).

Heavy infestations of a single weed species surviving herbicide treatment provide the best indication of resistance (Beckie et al, 2000). These are the situation of some grasses in Syria, but despite the simplicity and ease of justification such cases, scientific experiment to confirm herbicide-resistance to (ACCase) in our region is required. The experiment theoretically suppose that, the seeds which were selected from ICARDA center at Tel-Hadya putative susceptible biotype, , this is because of integrated crop management practices are followed in the station, and those collected from other locations putative resistant biotype for ACCase inhibitors, then the effectiveness results after application will prove or deny those hypotheses. Plant response to the herbicide is based on visual evaluation, mortality, or growth inhibition comparative to untreated grasses. Resistance is confirmed if the dose response of the biotypes is statistically different and the putative resistant biotype is not controlled at doses that control susceptible plants (Beckie et al, 2000). If the farmers cannot be convinced that 
herbicide-resistance in weeds will have a significant impact on their profits, they will not adopt measures to prevent its development. The cost of resistance is not only related to higher herbicide costs, we should note the costs involved with the additional number of times herbicides have to be applied, also there is further costs resulting from reduced yields because of the poorer weed control. If we calculate the theoretically estimated cost of herbicide-resistance at the national level in Syria, we will find that a huge amount of money was lost and was spent in vain, based on this fact we must persuade farmers to adopt anti-resistance strategies where the cost is much lower in comparison to the cost of resistance. The adoption of such strategies requires first identifying herbicide-resistant, monitoring their nature and distribution in our region. This article is one of the first studies on the herbicide-resistance in Syria that may tackle this phenomenon in details, and that can be further generalized on wider scale in future.

\section{MATERIAL AND METHODS}

Selection of a field site for collecting suspect weeds depends upon the objective. In some instances, specific areas are sampled in response to poor herbicide performance. Alternatively, site selection can be based on past herbicide use or cropping history (Beckie et al, 2000).

Seeds of grasses collected in 2010 summer from Quaik river flat near ICARDA from Al-Eis, Al-Hadher, and Banes, which assumed as herbicide resistant (ACCase) and from inside Tel-Hadya ICARDA center, which expected to be sensitive biotype, those seeds were preserved in paper bags at normal temperature and low humidity room, later they putted in the fridge to break dormancy phase. For many species, seeds are stored at room temperature at low humidity (40\% or less) for 1 to 4 mo (Adkins et al. 1997). For some species, storage at temperatures below freezing is more conducive to breaking dormancy (Anderson et al. 1998).

Locations had chosen upon practical experience in this region, as well as the demonstrations trials results that directly referred to herbicide-resistant. Wild oat, hood canary grass and short spike canary grass had collected from southwestern of Aleppo. Seeds collected in the previous year had planted in December 1, 2011 in sterile soil pots, each pot had coded to reflect the type of grass and collecting origin, Table 1 .

\begin{tabular}{|l|c|c|c|c|}
\hline \multicolumn{5}{|l|}{ Table.1 Collected grasses and their origins. Theory encoded $(\mathrm{N})$ normal, $(\mathrm{R})$ resistant. } \\
\hline Grasses & Al-Eis & Al-Hadher & Banes & Tel-Hadya \\
\hline Avena fatua. & AVEFA-R1 & AVEFA-R2 & AVEFA-R3 & AVEFA-N \\
\hline Phalaris paradoxa & PHAPA- R1 & PHAPA-R2 & & PHAPA-N \\
\hline Phalaris brachystachys & PHABR- R1 & PHABR-R2 & & PHABR-N \\
\hline
\end{tabular}

Each grass type encoded by location and species. It planted in 15 pots, then 10 pots had chosen because of good germination to facilitate the process of spraying. Five treatments including untreated control had applied. Two of those 
herbicides were ACCase inhibitors, Ralon Super (fenoxaprop-P-ethyl 69g/L) recommended dose (41.4 g a.i. ha-1) and Topik (clodinafobpropargyl $240 \mathrm{~g}$ ) dose (60.0 g a.i. ha-1), and two herbicides were ALS inhibitors, Atlantis OD (Mesosulfuron-methyl $10 \mathrm{~g}+$ Iodosulfuron-methyl $2 \mathrm{~g} / \mathrm{L})$ dose $(10.0 \mathrm{~g}$ a.i. $+2.0 \mathrm{~g}$ a.i. ha-1), and Pallas OD (Pyroxsulam 45g) dose (22.5 g a.i. ha-1) the untreated control sprayed by water only.

The discriminating dose is not defined as the recommended field (label) rate, although the latter may equal the former in some cases (Heap 1994). So the discriminating doses for this experiment are followed the label recommendation as well as the local experience in this region. Application date was April 3, 2012 where Azote Knapsack sprayer fitted with 4 flat fan nozzles 80.02, boom wide 2m, 250 liter/ha. Grasses stages were B22 - B30 (Uwe Meier, 2001).

The experiment carried out in strip-plot design in two replicates for two treatment factors, the biotypes from different sites and the herbicides, using pots as an experiment unit. This design adopted for its role in reducing the impact of leakage of chemical treatment applied between pots. Data were analyzed using analysis of variance (ANOVA) to assess main effects and interactions of the two factors, herbicide treatments and grasses, taking into account the error structure under the strip plot design in RCBD. Furthermore, residual plots were examined to support the ANOVA assumptions. Pairs of treatments of interest were compared using least significant differences (LSD) at 5\% level of significance. In order to study the similarity of herbicides in term of biotypes responses to herbicides treatments, we used hierarchical clustering analysis using Euclidean distance to form the similarity matrix and furthest neighbor (i.e. complete link) as clustering method.

Plant response to the herbicide is evaluated based on visual evaluation, mortality, and growth inhibition relative to untreated grasses. Resistance is confirmed if the dose response of the biotypes shows significant differences and the putative resistance biotype is not controlled at doses that control sensitive plants.

American method was used as an estimating scale (i.e. $0=$ Health Plant $100=$ Full Death $)$. Commercial formulation of the herbicide was applied using accurate sprayer. The efficacy evaluations have been taken 23 days after application.

\section{RESULTS AND DISCUSSION}

The primary hypothesis expected to find no resistance at Tel-Hadya's location, while herbicide-resistant for ACCase inhibitors are developed in other three locations. Results of efficacy revealed this expectation and show significant differences between the collect location treatments (Fpr <0.001). Grasses have been collected from all locations clearly reflects the good response of using (ALS) herbicide and the results were excellent, generally the efficacy results were $>85 \%$ with high level of similarity, this results are confirming that no resistant for ALS inhibitors. 
The (ACCase) herbicide reflected variable responses in term of locations; Tel-Hadya site (AVEFA-N) presented acceptable response to all herbicides, the efficacy results were $>60 \%$ which mean no herbicide-resistant for ACCase inhibitors. The other two locations Al-Hadher (AVEFA-R2) and Banes (AVEFAR3) reflected bad efficacy response, the efficacy were $<40 \%$, which mean clearly resistance for (ACCase) as we expected. Abnormal response was at AlEis location (AVEFA-R1), because of good response to the Topik herbicide results, which was almost $75 \%$ while Ralon was almost $40 \%$, obviously the herbicide-resistant in Al-Eis location was confusing, this contradicts the hypothesis, so it is appropriate to recommend to keep monitoring the wild oats in Al-Eis location.

In some areas of Syria Phalaris spp. can be found with high density and represented as dominant grass, Quaik river area can be considered as good example, canarygrasses can be noticed easily in wheat fields where the conventional methods are adopted, like the multiple tillage, continuously planting cereal and the rotation with cereals every second year at best probability, so the annual weeds are considered the most harmful comparing with perennial.

The (ACCase) herbicide reflected variable responses on hood canarygrass in term of collected locations. The Topik efficacy results was $>85 \%$, while Ralon was $<25 \%$ for seeds collected from Tel-Hadya site (PHAPA-N). As we know in advance Ralon is normally weak in controlling this grass (previous experience), so we can accept this outcome that function of (ACCase) will be represented only by Topik, therefor we can say that, no herbicide-resistant for ACCase inhibitors in this location. The other locations Al-Eis (PHAPA-R1) and Al-Hadher (PHAPA-R2) reflected bad efficacy < 40\%, which means clear resistance for (ACCase) as we assumed in advance.

The (ACCase) herbicide reflected bad response on short spike canarygrass for all locations, including Tel-Hadya site. The efficacy results for Topik and Ralon were $<45 \%$, this contradicts with the hypothesis. Herbicide-resistant for ACCase inhibitors in Tel-Hadya (PHABR-N) location may be the most important conclusion and unexpected result in this trial, while the results were bad as assumed in the other locations Al-Eis (PHABR-R1) and Al-Hadher (PHABR$\mathrm{R} 2)$.

The wild oat results in different locations were encoded with herbicide's name, example (Banes-A), which means wild oat sampling from Banes and treated by Atlantis. The hierarchical clustering analyses clearly separated the sensitive biotypes (S) than resistant biotypes (R). The results reflects an excellent responses when using Atlantis and Pallas herbicides in all locations, those results confirm that no resistant for ALS inhibitors found. On the other hand variable responses when using Topik and Ralon herbicides related to different locations has been noticed. 


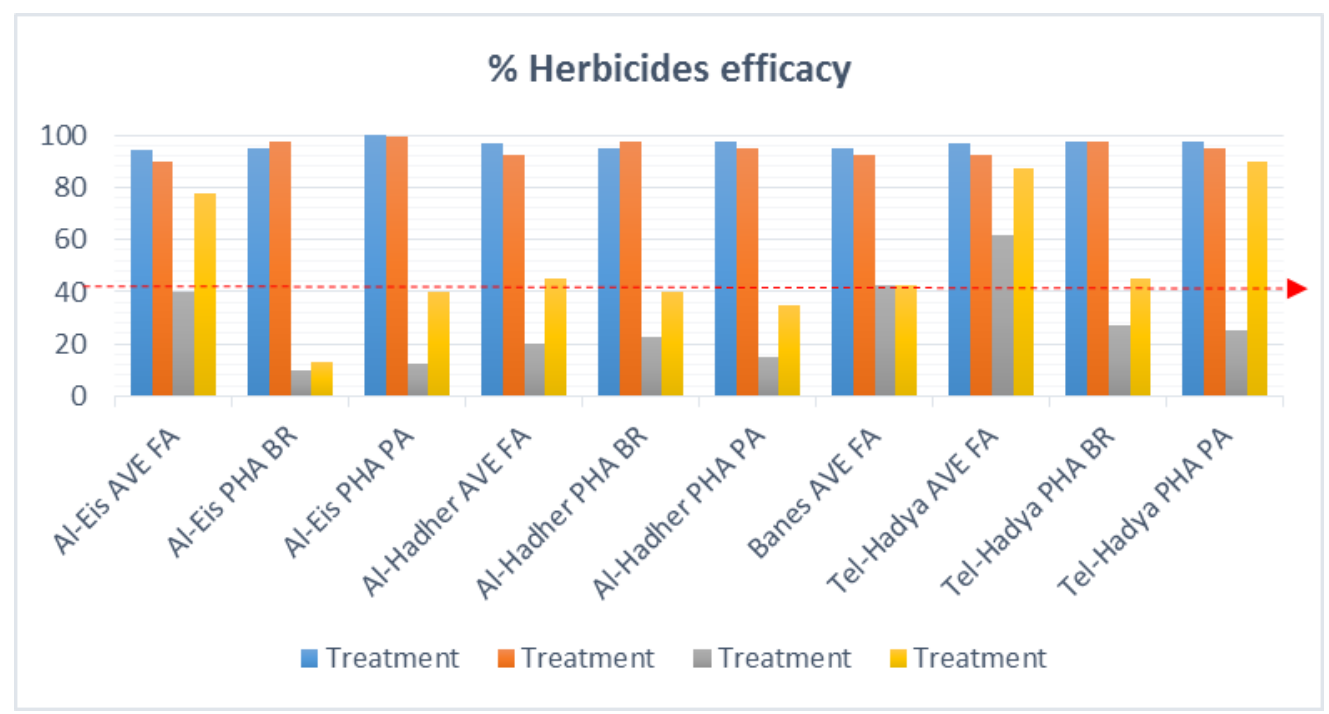

Figure 1. Herbicides efficacy in controlling grasses form different locations.

ACCase inhibitors works well in Tel-Hadya location, so it takes place in sensitive group (left), but the wild oat sampling from Al-Hadher and Banes had been located clearly in resistant group (right). The wild oat sampled from Al-Eis was still confusing, it takes place in two groups due to the use of Ralon or Topik, so we cannot confirm or deny the resistance.

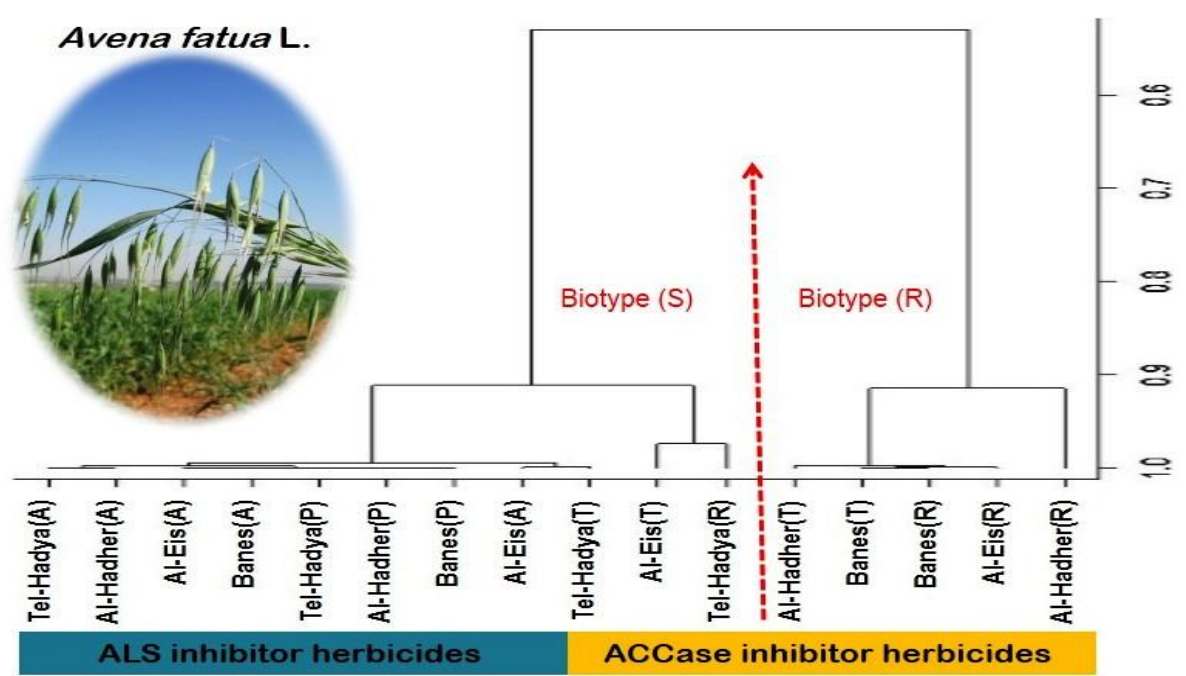

Figure 2. Level of similarity depends on encoded name (AVEFA) with herbicide related and activity results. 
The hierarchical clustering analyses for hood canarygrass have presented two separate groups clearly, the sensitive biotypes (S) (left), and the resistant biotypes (R) (right). The results reflects the excellent responses when using Atlantis and Pallas herbicides at all locations, this confirm no resistant for ALS inhibitors. While ACCase herbicide showed variable responses related to different locations. Tel-Hadya hood canarygrass is still sensitive when treated by Topik, and this is consistent with the theory. On the other hand, the same biotype which was treated by Ralon located in the resistant group, this is normal as we know the weakness of this product in controlling Phalaris sp. The hood canarygrass had been collected from Al-Eis and Al-Hadher clearly located in the resistant group.

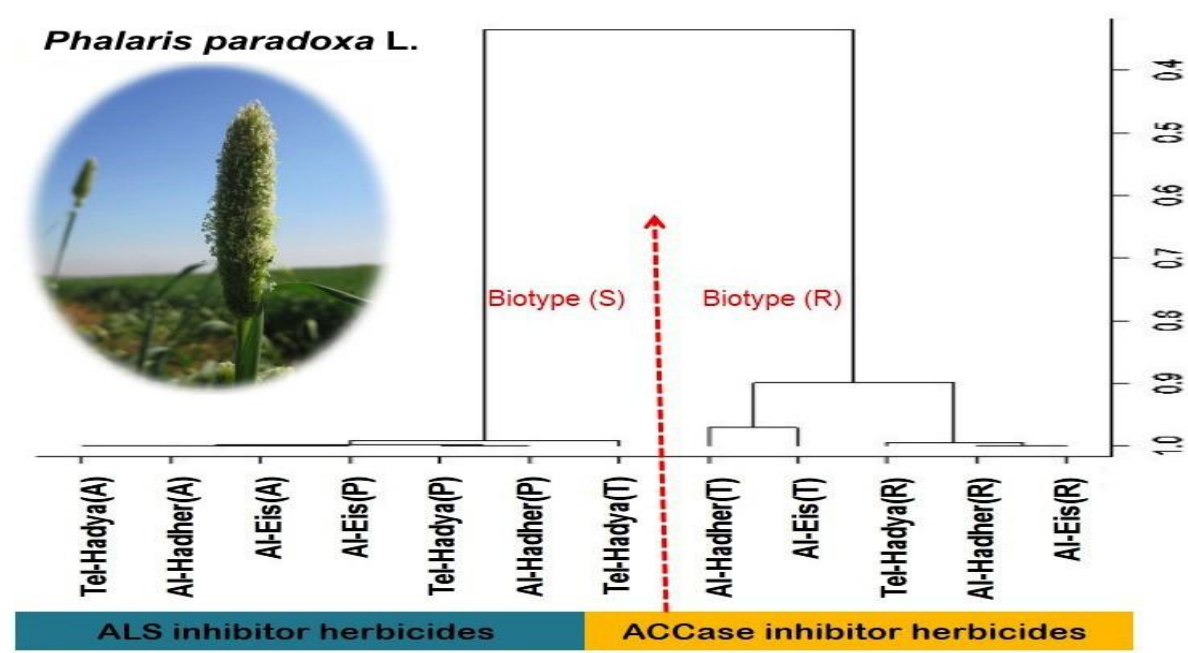

Figure 4. Level of similarity depends on seed code name PHABR with herbicide related activity results.

\section{CONCLUSIONS}

According results can be concluded that, the short spike canarygrass is the most dangerous in this area related resistant issue, where resistance demonstrated to (ACCase) in all locations including Tel-Hadya station. The hood canarygrass comes second in terms of severity, as demonstrated by its resistance to a (ACCase) at all locations except Tel-Hadya station. Finally the wild oat comes third in term of severity, as demonstrated by its resistance to a (ACCase) in both locations Al-Hadher and Banes while Al-Eis site was doubtful, hence Tel-Hadya station grass was sensitive.

\section{REFERENCES}

Adkins, S. W., D. Wills, M. Boersma, S. R. Walker, G. Robinson, R. J. McLeod, and J. P. Einam. 1997. Weeds resistant to chlorsulfuron and atrazine from the north-east grain region of Australia. Weed Res. 37: 343-349. 
Anderson, D. D., F. W. Roeth, and A. R. Martin. 1998. Discovery of a primisulfuronresistant shattercane (Sorghum bicolor) biotype. Weed Technol. 12:74-77.

Bandeen, J.D., G.R. Stephenson and E.R. Cowett. 1982. The Discovery and Distribution of Herbicide Resistant Weeds in North America. In: Herbicide Resistance in Plants (ed. LeBaron H.M. and J. Gressel). New York John Wiley \& Sons. pp. 9-30.

Beckie, H. J., A. G. Thomas, A. Le'ge`re, D. J. Kelner, R. C. Van Acker, and S. Meers. 1999b. Nature, occurrence, and cost of herbicide-resistant wild oat (Avena fatua) in small-grain production areas. Weed Technol. 13: 612-625.

Beckie, H. J., A. G. Thomas, and A. Le'ge`re. 1999a. Nature, occurrence, and cost of herbicide-resistant green foxtail (Setaria viridis) across Saskatchewan ecoregions. Weed Technol. 13:626-631.

Beckie, H. J., Heap, I. M., Smeda, R. J., and Hall, L. M., 2. Screening for Herbicide Resistance in Weeds1. Weed Technology. 2000. Volume 14:428-445.

Browse, J. and C. Somerville. 1991. Glycerolipide synthesis: biochemistry and regulation. Ann. Rev. Plant Physiol. Plant Mol. Biol. 42: 267-506.

Heap, I. M. 1994. Identification and documentation of herbicide resistance. Phytoprotection 75(Suppl.):85-90.

Ryan, G.F. 1970. Resistance of common groundsel to simazine and atrazine. Weed Science 18: 614-616.

Uwe Meier. 2001. Growth stages of mono-and dicotyledonous plants. Federal Biological Research Center for Agriculture and Forestry.

[WSSA] Weed Science Society of America. 1998. "Herbicide resistance" and "herbicide tolerance" defined. Weed Technol. 12: 789.

[WSSA] Weed Science Society of America. 2004. www.weedscience.org website. Accessed 1 Aug., 2004.

[WSSA] Weed Science Society of America. Graphs PowerPoint was made from data accessed from the survey website at www.weedscience.org on March 18th, 2014. Ian Heap. 